\title{
Gram per Animal per Week
}

National Cancer Institute

\section{Source}

National Cancer Institute. Gram per Animal per Week. NCI Thesaurus. Code C73715.

A dose calculation unit expressed in gram(s) per animal per period of time equal to seven days. 